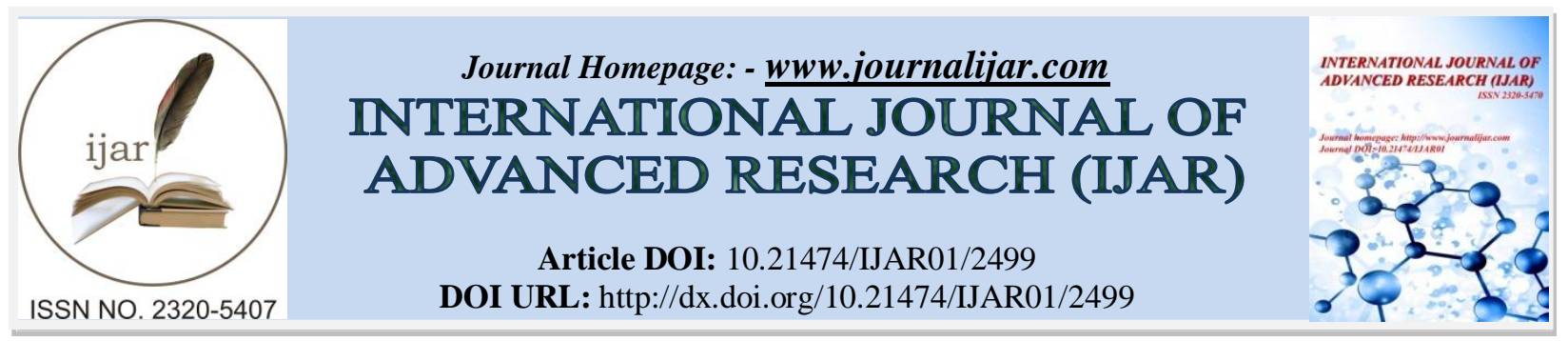

RESEARCH ARTICLE

\title{
LEVEL OF PHYSICAL ACTIVITY DURING PREGNANCY: WOMEN'S PERCEPTION AND ITS
} MODIFIABLE BARRIERS.

\author{
Ayman Abdullah Bukhari ${ }^{1}$, Bayan Abdulrahman Al-Deibani ${ }^{2}$, Bodour Saleh Alsalmi ${ }^{2}$, Amani Faleh \\ Alhakami ${ }^{2}$ and Nada Hamed Alsafari ${ }^{2}$. \\ 1. Assistant professor and consultant in Obstetrics and Gynecology. \\ 2. Medical intern KAU.
}

\section{Manuscript Info}

Manuscript History

Received: 25 October 2016

Final Accepted: 23 November 2016

Published: December 2016

Key words:-

physical activity during pregnancy,

women's perception and belives,

modifiable barriers

\section{Abstract}

Background: Traditionally, pregnant women have been advised to restrict exercise due to concerns for the health of the mother and her fetus, while regular exercise has also been has a role in managing stress, depression and gestational diabetes . An awareness that exercise is important in promoting health and well-being has led to many women wanting to continue exercising during.

Method: This cross sectional study carried out among pregnant women who attend King Abdulaziz University hospital as outpatients or inpatients by distributing a questionnaire consist of ( demographic data, perception of physical activities during pregnancy, awareness of physical activities benefits), 300 accepted to enroll in the study.

Result: Sample of 300 pregnant women participated in the study $65.3 \%$ of pregnant women were not exercising during pregnancy, $1 \%$ relived that they dislike exercise,5.3\% of them have work related barriers, $13.3 \%$ having no time, $15.4 \%$ dined having any kind of motivation, $32 \%$ have no knowledge about the benefit of exercise, and $33 \%$ have pregnancy related barriers. While $35 \%$ were exercising during pregnancy $88.7 \%$ of them believe physical activity and exercise during pregnancy will improve their labor and delivery

Conclusions: We found that most pregnant women were not physically active during pregnancy, we recommend the physician and health care provider to motivate them to be more active . More awareness campignes should be held.

Copy Right, IJAR, 2016,. All rights reserved.

\section{Introduction:-}

Increasing evidence supports the importance of exercise for individual health. Being active can reduce the risk of diseases such as osteoporosis, cardiovascular disease, type II diabetes, gestational diabetes , hypertension , decreasing the rate of lower back pain colon cancer, and obesity, $(\mathbf{1 , 2 , 3})$ regular exercise has also a role inmanaging stress, depression, boosting self-esteem and enhancing body image. (3), also it has good influence on the neonates such as reducing the rate of preterm delivery . (4)The increasing in awareness level about the importance of exercise in promoting health and well-being has led to many women wanting to continue exercising during pregnancy. However regarding tradition thinking pregnant women have been advised to restrict exercise due to concerns for the health of the mother and her fetus, including risks of overheating; impaired delivery of oxygen and 
nutrients to the fetus; and premature labour(5). A lot of speculation regarding the adverse effects of exercise on pregnancy outcome due to culture and social percenters . with no scientific supporting . (6)The physical stress arising from leisure exercise has not been shown to increase the incidence of small for gestational age babies or premature labour; and may even decrease the incidence of both ( 7). During the last few decades a huge dramatically changes happened towards practicing exercises during pregnancy .(8)higher amounts of exercise have been associated with a reduced incidence of caesarean section and shorter hospitalization (9), Alsoamongwomen who deliver vaginally, physical fitness may also be associated with a shorter duration of active labor(9). On the basis of such evidence, American Congress of Obstetricians and Gynecologistsrecommendedon 2002 as update for its 1985 guideline that pregnant women can exercise moderately for 30 minutes on most days of the week, and in 2008 the U.S. Department of Health and Human Services published its guidelines and recommende pregnant women to participate in moderate physical activities at least 150 minutes per week ,in accordance with these recommendations, irrespective of the pregnant woman's physical fitness level, exercise should be low-impact, moderate-intensity, and regular. $(\mathbf{9 , 1 0 , 1 1 ) I n ~ s p i t e ~ o f ~ t h e s e ~ f a c t s ~ a n d ~ r e c o m m e n d a t i o n , ~ i t ~ i s ~ s u b m i t t e d ~ t h a t ~ w o m e n ~ a r e ~}$ not meeting the exercise recommendations of the previous studies. A myriad of factors not limited to beliefs and attitudes of women with respect to exercise in pregnancy, level of knowledge, level of education, safety concern of the pregnant woman andher physician, race/ethnicity, and previous involvement in regular exercise have been implicated as important factors predisposing to exercise engagement or phobia among pregnant women . $(9,10,11)$ This study focused on measuring awareness level of physical activity among pregnant women by using useful questionnaires in this regard., in order to identify factors that affect beliefs and behaviors would objectively encourage a change in attitude.

\section{Method:-}

\section{Ethicalapproval:-}

The study was approvedfrom the ethical committee in faculty of medicine - King Abdulaziz University.

\section{Study design:-}

This cross-sectional survey, targeted pregnant women population who admitted to the inpatient department or visited the obstetrics and gynecology clinic from September2015 to Novemer2015 atking Abdul-Aziz University hospital in Jeddah

Three hundred fifty six pregnant women werecruised to fill the questionnaires and from them only 56 refused to participate so the total responds were 300 .

\section{Questionnaires and measurements:-}

The method of the study was adapted questionnaire from 40 articles the piloting was done on eight pregnant women it takes around 10 minutes to fill the survey.The subject informed about the purposes of this study and theconsent was taken. The questionnaire consists of different parts. First part was about personal information such as; name, nationality, address and phone number. Then ten multiple choices questions about the socio-demographic information included; age, race, residence, education, occupation status, income, body mass index, pregravida, BMI, general health and smoking. Thethird part was about women's obstetric history including the parity, pregnancy trimester, and total numbers of prenatal visits, place of prenatal care, any complication during pregnancy and any history of preterm stillbirth, abortion and mode of delivery. In this part collected information about women physical activity level including whether the subject habitually exercise before pregnancy or started during this pregnancy, what are the type of exercise,the duration of each session and what are the sources for their information about physical activity. The last part focused on the women's perception about the physical activity, if there any benefit of it and whether it consider safe to do it and the barrier.

\section{Statistical analysis:-}

For the data analysis and processing SPSS, version 20 used. Descriptive statistics ( number and percentage) was used for nonparametric data (demographic data, level of Exercise during this pregnancy, Modifiable barriers to physical activity during pregnancy and sources of physical activity (reported in percentage)) . Comparison done to assess the relationship between Pregnancy trimester, educational level, monthly income and occupation as categories and the Women's perception and belief by using Chisquare test with a set statistical significance cutoff of $\mathrm{p}<0.05$. 


\section{Results:-}

Tabel1showed the demographic characteristics of the 300 pregnant women participated in the study, of which $45 \%$ were from group age 20-29, more than half (57.7\%) had university degree \& reported multiparty, third quarter of the women (76.7\%) were housewives . (Table 1) Almost two third (65.3\% ) were not exercising during pregnancy, and when asking them about the barriers that prevent them to do the exercise $1 \%$ relived that they dislike exercise,5.3\% of them have work related barriers (such as being too tired from work, not having enough time because of work duties or having a physically active job), $13.3 \%$ having no time (i.e. having a lot of child care activities, school or cleaning up), $15.4 \%$ dined having any kind of motivation (i.e. having no one to go with),32\% have no knowledge about the benefit of exercise (i.e. lack of personal knowledge or inadequate advice provided from a health professional) and 33\% have pregnancy related barriers (i.e. these included morning sickness, back pain and high risk pregnancies).

Table 1:- Demographic Characteristics of the sample

\begin{tabular}{|l|l|}
\hline Demographic data & N (Percent) \\
\hline Age & \\
$<20$ & $2 \%$ \\
$20-24$ & $18.3 \%$ \\
$25-29$ & $26.7 \%$ \\
$30-34$ & $28 \%$ \\
$>=35$ & $25 \%$ \\
\hline Education & \\
Primary school & $5.7 \%$ \\
High school & $36.7 \%$ \\
University & $57.7 \%$ \\
\hline Occupation & \\
Housewife & $76.7 \%$ \\
Worker & $20.7 \%$ \\
Student & $2.7 \%$ \\
\hline Previous history of: & \\
Preterm & $3 \%$ \\
Stillbirth & $3.7 \%$ \\
Abortion & $28 \%$ \\
No history & $65.3 \%$ \\
\hline Parity: & \\
Null parity & $30.3 \%$ \\
One parity & $19.7 \%$ \\
Multiparty & $50 \%$ \\
\hline
\end{tabular}

Table2showed women's perception and belief about physical activity during pregnancy, almost third quarters $(72.3 \%)$ reported that pregnant women can can continue their regular exercise during pregnancy on ar regular bases ( 3 times/ week) and the majority of the participant stated the knowing of the benefits of practicing regular exercise during pregnancy. (Table 2) The participants reported several sources about information of physical activity. (figure 1)

Table 2:- Comparing women's perception and belief about physical activity

\begin{tabular}{|r|c|c|}
\hline Variables & $\mathrm{N}$ & $\%$ \\
\hline Women's perception & $\mathbf{2 1 9}$ & $\mathbf{7 3 . 5}$ \\
\hline $\begin{array}{r}\text { A. } \ldots \text { most women can continue their regular exercise during } \\
\text { pregnancy. }\end{array}$ & $\mathbf{1 1 1}$ & $\mathbf{3 7 . 4}$ \\
\hline $\begin{array}{l}\ldots \text { most women who never exercised can begin an exercise program } \\
\text { during pregnancy. }\end{array}$ & $\mathbf{1 7}$ & $\mathbf{5 . 7}$ \\
\hline $\begin{array}{l}\ldots \text { for a pregnant woman, it is OK to continue to exercise even if she } \\
\text { becomes tired or exhausted. }\end{array}$ & $\mathbf{2 1 6}$ \\
\hline $\begin{array}{l}\text { is better than activity done irregularly } \\
\text { or less often. }\end{array}$ & $\mathbf{1 7 2}$ & $\mathbf{5 7 . 9}$ \\
\hline E. $\ldots$ pregnant women should not exercise while lying down on their
\end{tabular}




\begin{tabular}{|c|c|c|c|}
\hline \multicolumn{4}{|c|}{ back during the first trimester. } \\
\hline & $\begin{array}{l}\text {... pregnant women should not exercise while lying down on their } \\
\text { back during the second trimester. }\end{array}$ & 89 & 30 \\
\hline G. & $\begin{array}{l}\text {... pregnant women should not exercise while lying down on their } \\
\text { back during the third trimester. }\end{array}$ & 119 & 40.1 \\
\hline $\mathrm{H}$. & $\begin{array}{l}\text {... long periods of standing in one place without moving should be } \\
\text { avoided while pregnant. }\end{array}$ & 245 & 82.2 \\
\hline \multicolumn{4}{|c|}{ Benefits } \\
\hline & $\begin{array}{l}\text {... pregnant women will gain some benefit from doing exercise } \\
\text { during her pregnancy. }\end{array}$ & 279 & 93.6 \\
\hline B. & $\begin{array}{l}\text {... physical activity and exercise during pregnancy might make a } \\
\text { woman feel more energetic. }\end{array}$ & 261 & 87.6 \\
\hline C. & $\begin{array}{l}\text {... physical activity and exercise during pregnancy will improve a } \\
\text { woman's labor and delivery. }\end{array}$ & 266 & 89.3 \\
\hline D. & $\begin{array}{l}\text {... physical activity and exercise during pregnancy will improve the } \\
\text { health of the baby. }\end{array}$ & 167 & 56.2 \\
\hline & $\begin{array}{l}\text {... physical activity and exercise during pregnancy causes lower } \\
\text { weight babies. }\end{array}$ & 38 & 12.8 \\
\hline
\end{tabular}

Figure 1:- The sources of information about physical activity.

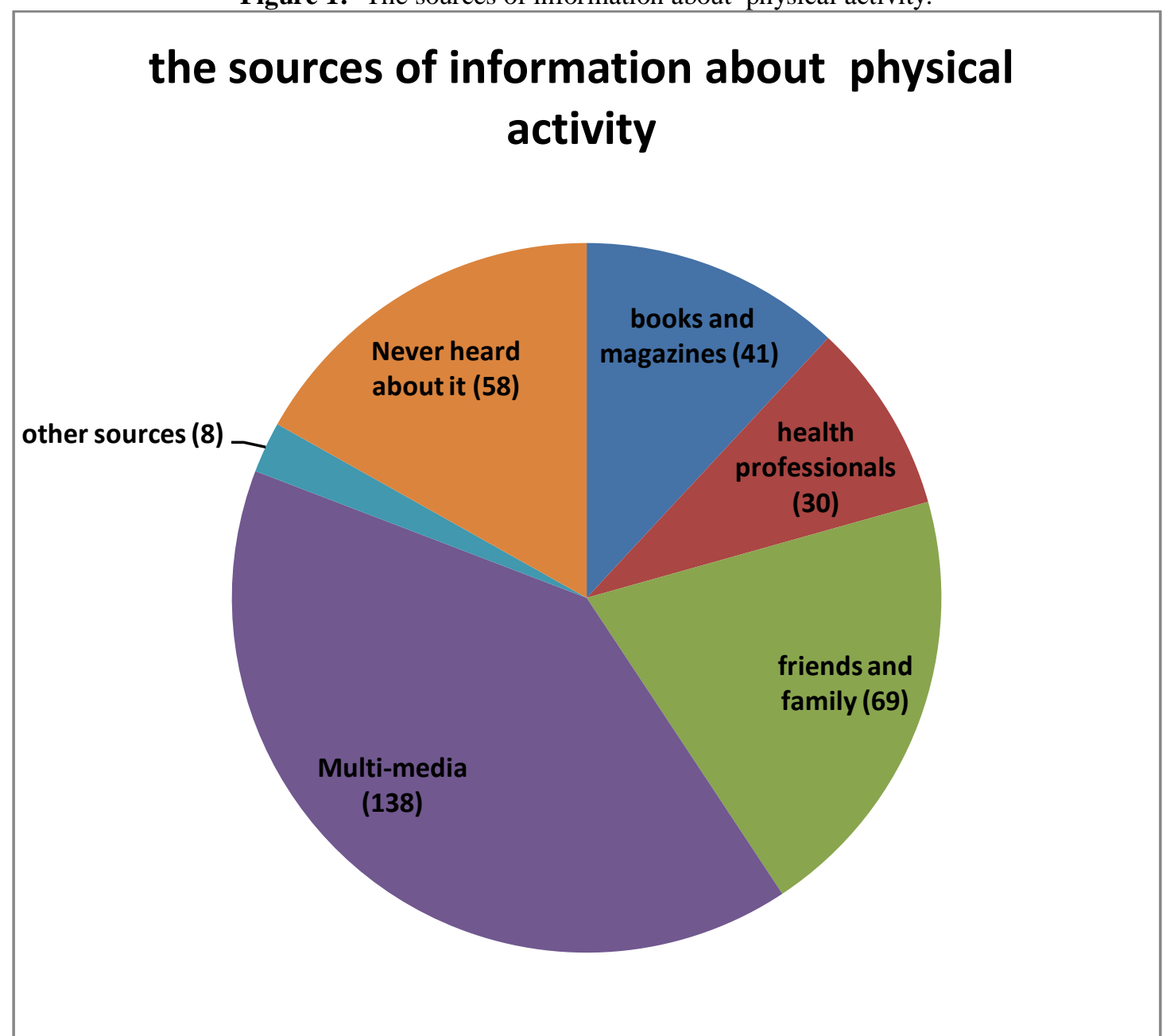

The results showed that workers women and from group higher monthly income have good perceptions of physical activities during pregnancy with no significant difference, while there was significant association between women with higher level of education (University level) and good perceptions of physical activities in the following items 
(continue exercises during pregnancy on a regular basic $\mathrm{p}=0.008$, avoiding standing in one place for a long time $\mathrm{p}=0.03$ ) . Regarding the comparison of women's perception depending of pregnancysemester , the results showed high perception of physical activities benefits during pregnancy among women in the third trimester followed by women in the second trimester with no significant difference .

Table 3:- Women's perception and belief about physical activity during pregnancy in this sample comparing with one study in University of North Carolina, US.

\begin{tabular}{|l|l|l|}
\hline $\begin{array}{l}\text { Benefits of exercise and physical activity during pregnancy: } \\
\begin{array}{l}\text { pregnant women will gain some benefit from doing exercise } \\
\text { during her pregnancy }\end{array}\end{array}$ & $\begin{array}{l}\text { Overall } \mathrm{n}=300 \\
\text { \%Agree(n) } \\
\text { In this study }\end{array}$ & $\begin{array}{l}\text { Overall } \mathrm{n}=1306 \\
\text { \%gree(n) } \\
\text { North Carolina }\end{array}$ \\
\hline $\begin{array}{l}\text { physical activity and exercise during pregnancy might make a } \\
\text { woman feel more energetic }\end{array}$ & $\mathbf{9 3 . 0}(\mathbf{2 7 9})$ & $\mathbf{9 7 . 9}(\mathbf{1 2 7 5})$ \\
\hline $\begin{array}{l}\text { physical activity and exercise during pregnancy will improve a } \\
\text { woman's labor and delivery }\end{array}$ & $\mathbf{8 7 . 0 ( \mathbf { 2 6 1 } )}$ & $\mathbf{9 4 . 3 ( 1 2 2 5 )}$ \\
\hline $\begin{array}{l}\text { physical activity and exercise during pregnancy will improve the } \\
\text { health of the baby }\end{array}$ & $\mathbf{8 8 . 7}(\mathbf{2 6 6})$ & $\mathbf{9 4 . 4 ( 1 2 2 3 )}$ \\
\hline $\begin{array}{l}\text { physical activity and exercise during pregnancy causes lower } \\
\text { weight babies }\end{array}$ & $\mathbf{5 5 . 7}(\mathbf{1 6 7})$ & $\mathbf{7 4 . 7 ( 9 6 4 )}$ \\
\hline
\end{tabular}

\section{Discussion:-}

Several studies addressed the important and the great benefits of physical exercises practicing during pregnancy and after delivery, also they demonstrated that there is no risk on fetus and neonates, and had good influence on lifestyle.(12,13)A lot of body's changes happened to to pregnant women which decreased the ability of performance for some kind of exercises. (12)The current studies showed that only 34.7\% pregnant women practice physical activities during pregnancy which was lower comparing with the rate of USA study where the authors reported 93.3\% of pregnant women practicing exercise during pregnancy (3) and Nigeria study (81.9\%). (14), while in other USA study the rate was $15.8 \%$ and in Irland study $21.5 \%$. (13)The main reasons of not exercising in this sample were pregnancy-related barriers (33\%) (i.e. these included morning sickness, back pain and high risk pregnancies),in Brazil study Lack of time, feeling tired and uncomfortable were the principal reasons given by the women for not exercising (8) while in Australia study there was six barriers (work burden, exhaustion, pregnancy- symptoms, active with no guidelines, shortage of motivation, and deficiency in the level of knowledge \&recommendations).(2)Among all women who exercised during pregnancy walking was the leading activity $(60.7 \%)$, similar to that the results from Pennsylvania , USA study where authors reported that $81.6 \%$ pregnant women reported slow walking, (15)while $(59.8 \%)$ of Nigerian pregnant women practicing relaxation and breathing the most (10) and in second Nigerian study Aerobic (43.5\%) and stretching (33.4\%) were the common exercises .(14)A , compared a comparison between the findings from the current study with the one from University of North Carolina, USabout women's perception and belief about physical activity during pregnancy was Illustrated in Table3 and showed improvementin the level of knowledge about the benefit of physical activities during pregnant. (11).

\section{Limitation:-}

Few limitations of the study should be noted. As majority of women were in their 2nd trimester, Physical activity perceptions may change throughout pregnancy, the sample size considered small, the study conducted at king AbdulAziz University hospital in Jeddah which is a coastal city doesn't properly represent the population in Saudi Arabia as well as some villages around Jeddah were not assessed and we suspect the results will be different due to the culture reasons.

\section{Conclusion:-}

Most pregnant women were not physically active during pregnancy and of their knowledge about the physical activity was from multimedia, and some of these information were not scientifically correct. We recommend the physician and health care provider to motivate them to be active as the British college recommended and heldmore awareness events lead by physician to provide pregnant women by the correct information, also advise women to attend prenatal exercise classes supervised by experienced trainer. 


\section{References:-}

1. Nascimento SL1, Surita FG2, Godoy AC2, Kasawara KT2, Morais SS. Physical Activity Patterns and Factors Related to Exercise during Pregnancy: A Cross Sectional Study.PLoS One. 2015;10(6):e0128953.

2. Connelly M1, Brown H2, van der Pligt P3, Teychenne M4. Modifiable barriers to leisure-time physical activity during pregnancy: a qualitative study investigating first time mother's views and experiences. BMC Pregnancy Childbirth. 2015 Apr 22;15:100.

3. Borodulin KM1, Evenson KR, Wen F, Herring AH, Benson AM. Physical activity patterns during pregnancy. Med Sci Sports Exerc. 2008;40(11):1901-8.

4. Domingues MR, Matijasevich A, Barros AJD, Santos IS, Horta BL, and Hallal PC. Physical Activity during Pregnancy and Offspring Neurodevelopment and IQ in the First 4 Years of Life.PLoS One. 2014; 9(10): e110050.

5. Duncombe D1, Wertheim EH, Skouteris H, Paxton SJ, Kelly L. Factors related to exercise over the course of pregnancy including women's beliefs about the safety of exercise during pregnancy. Midwifery. 2009 ;25(4):430-8.

6. Downs DS, Taber LC, Kelly Evenson R, Leiferman J, and YeoSA. Physical Activity and Pregnancy: Past and Present Evidence and Future Recommendations. Res Q Exerc Sport. 2012 ; 83(4): 485-502.

7. Mudd LM1, Nechuta S, Pivarnik JM, Paneth N; Michigan Alliance for National Children's Study. Factors associated with women's perceptions of physical activity safety during pregnancy.Prev Med. $2009 ; 49(2-$ 3):194-9.

8. Ribeiro CP1, Milanez H. Knowledge, attitude and practice of women in Campinas, São Paulo, Brazil with respect to physical exercise in pregnancy: a descriptive study.Reprod Health. 2011 3;8:31.

9. Tinloy J1, Chuang CH2, Zhu J3, Pauli J4, Kraschnewski JL5, Kjerulff KH6. Exercise during pregnancy and risk of late preterm birth, cesarean delivery, and hospitalizations. Womens Health Issues. 2014;24(1):e99e104.

10. Mbada CE1, Adebayo OE1, Adeyemi AB2, Arije OO3, Dada OO4, Akinwande OA5, Awotidebe TO1, Alonge IA. Knowledge and Attitude of Nigerian Pregnant Women towards Antenatal Exercise: A CrossSectional Survey. ISRN Obstet Gynecol. 2014:260539

11. Evenson KR1, Bradley CB. Beliefs about exercise and physical activity among pregnant women. Patient EducCouns. 2010;79(1):124-9.

12. Ghodsi Z, Asltoghiri M. Does exercise training during pregnancy affect gestational age and gestational weight gain?. Procedia - Social and Behavioral Sciences.2012;31: 418 -22.

13. Nascimento SL, Surita FG, Cecatti JG. Physical exercise during pregnancy: a systematic review.CurrOpinObstet Gynecol. 2012;24(6):387-94 .

14. Mbada CE, Adebayo OE, Awotidebe TO, Faremi FA, Oginni MO, Ogundele AO, Emechete AI. Practice and Pattern of Antenatal and Postnatal Exercise among Nigerian Women: A Cross-Sectional Study. International Journal of Women's Health and Reproduction Sciences.2015; 3(2):93-8.

15. Kraschnewski JL1, Chuang CH, Downs DS, Weisman CS, McCamant EL, Baptiste-Roberts K, Zhu J, Kjerulff KH. Association of Prenatal Physical Activity and Gestational Weight Gain: Results from the First Baby Study. Womens Health Issues. 2013;23(4):e233-8. 